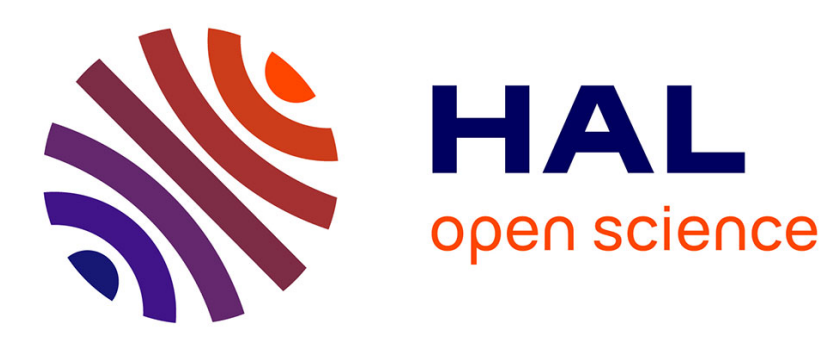

\title{
A New Criterion to Jointly Design the Antenna and Optimize the Communication Capacity in IR-UWB.
}

Dorin Panaitopol, Jocelyn Fiorina, Antoine Diet, Nicolas Ribière-Tharaud

\section{To cite this version:}

Dorin Panaitopol, Jocelyn Fiorina, Antoine Diet, Nicolas Ribière-Tharaud. A New Criterion to Jointly Design the Antenna and Optimize the Communication Capacity in IR-UWB.. IEEE Wireless Communications and Networking Conference, WCNC, May 2009, Budapest, Hungary. pp.PHY 6.1. hal00445983

\section{HAL Id: hal-00445983 \\ https://hal.science/hal-00445983}

Submitted on 11 Jan 2010

HAL is a multi-disciplinary open access archive for the deposit and dissemination of scientific research documents, whether they are published or not. The documents may come from teaching and research institutions in France or abroad, or from public or private research centers.
L'archive ouverte pluridisciplinaire HAL, est destinée au dépôt et à la diffusion de documents scientifiques de niveau recherche, publiés ou non, émanant des établissements d'enseignement et de recherche français ou étrangers, des laboratoires publics ou privés. 


\title{
Design of an UWB antenna and impact of the resulting pulse shape on the communication capacity
}

\author{
Dorin Panaitopol, Jocelyn Fiorina, Antoine Diet, Nicolas Ribiere-Tharaud
}

\begin{abstract}
This paper presents the impact of the antenna design over the capacity of a IR-UWB system in a Multi-User Interference environment. A new antenna design is proposed and it is showed using a new performance criterion that for this design, the communication capacity given by the Sholtz's pulse [13] might be reached using some other types of pulses.
\end{abstract}

Index Terms-IR-UWB, Kurtosis, Capacity, Antenna

\section{INTRODUCTION}

W IRELESS communications systems have, for some years now, focused on the concept of a spread spectrum technique known as Ultra Wide Band. From an antenna point of view, the Ultra Wide Band (UWB) concept covers today three major types of applications [1]:

i) Applications such as Ground Penetrating Radars (GPR, $1 \mathrm{MHz}$ to $10 \mathrm{GHz}$ ),

ii) Multi-narrowband applications such as signal intelligence and detection,

iii) Modern UWB operating in a 3.1 to $10.6 \mathrm{GHz}$ frequency band.

Impulse Radio UWB, where very low power pulses are transmitted, is meant to be used for ad-hoc sensor networks with high density of users where multi-user interferences may be heavy. Antennas dedicated to such applications are not supposed to be multi-harmonics but they are required to be really non-dispersive and wideband, as illustrated on Figure 1. Furthermore, phase transfer response must be linear with respect to frequency and ideally for any direction of emission. A performance criterion we propose to investigate is also the impact of the impulse shape created by the antenna on the multi-user interferences. Depending on the pulse shape, the interference may not have a Gaussian distribution and the distribution form affect the capacity of the communication link.

\section{AN ANTENNA FOR IR-UWB}

UWB antennas history begins with the work of Maxwell followed by Bose, Marconi, Amstrong and Carter with biconical 3D antennas. It goes on with horns and spherical fat structures with interesting wideband properties (Lindenbald, Schelkunoff, Friis, Kings and Kraus). In 1940, arguing that

Dorin Panaitopol \{dorin.panaitopol@supelec.fr\} and Jocelyn Fiorina \{jocelyn.fiorina@supelec.fr\} are with TELECOM Department at SUPELEC;

Antoine Diet \{antoine.diet@lss.supelec.fr\} and Nicolas Ribiere-Tharaud \{nicolas.ribiere-tharaud@1ss.supelec.fr\} are with LSS Department at SUPELEC
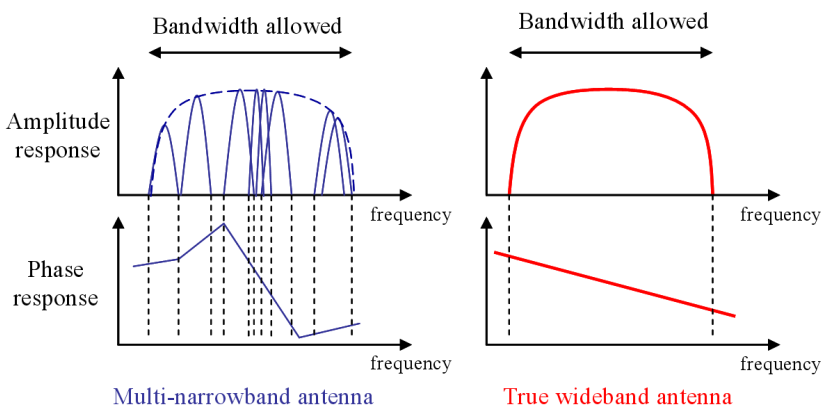

True wideband antenna

(a)

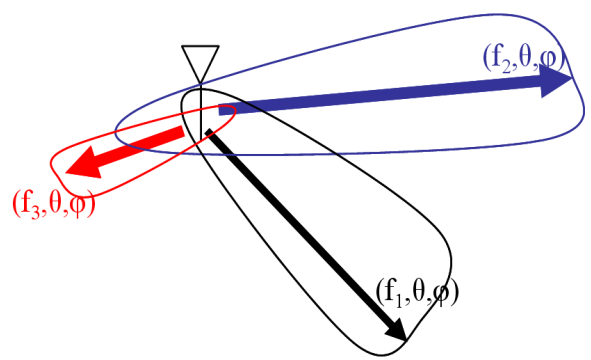

$\mathrm{H}(\mathrm{f}, \theta, \varphi)=\mathrm{H}_{\theta}(\mathrm{f}, \theta, \varphi) \hat{\theta}+\mathrm{H} \varphi(\mathrm{f}, \theta, \varphi) \hat{\varphi}$

(b)

Figure 1. Definition of wideband antenna (a) and frequency variation of main lobe (b)

the stored reactive energy is reduced in bulbous antenna due to smaller current concentration in thick structures, Kings claims that "fatter is better" for the design of such antennas [2]. Then, a lot of work has been done on volumetric curve based or tapered antenna (Schekulnoff, Friis, Marié and Stöhr). A great contribution, concerning the frequency independence of some structures (based only on angles), has been added by Rumsey. This was the introduction of spiral and log-periodic antennas, although the latter are dispersive due to phase centre translation in frequency. Nowadays, modern UWB antennas have to account for several considerations: matching properties (which leads to tapered profiles), minimum reactive power and hence resonance (which leads to thick or bulbous structures), low cost and small size (which leads to printed antennas). Several technologies, already proposed for lower frequency band applications can be used to realize wideband antennas. Interesting states of the art about the latter are given in [3], [4], 
[5]. The most important constraint is to build a non-resonant structure, which generally implies wide bent surfaces of conductor printed on substrates. Traveling wave structures are also preferred because they allow avoiding geometric resonances. Considering practical realization requirements (size and cost), the printed antenna is very popular for UWB. The geometry is first designed for a wide radiation pattern and, then, optimized for frequency matching. It seems that thick printed structures offer the wideband behavior necessary for UWB in a first step, bent shapes being chosen to radiate with large beam-width. In [6], the author suggests to take care about the free space attenuation applied in a wideband signal transmission arguing about the complementarity between constant aperture and constant gain antenna. Also the shape of the radiation pattern (DDR) has to be conserved in function of the frequency, and in function of the polarization at the same time, to avoid an amplitude compression effect, see Figure 1. The dispersion that can be observed on radiated pulses reveals the antenna time behavior. Integration and production of UWB mobile transceivers imply an additional task that consists in building a minimum-size low-cost antenna. These considerations lead to avoid volumetric structures (i.e., bi-conical, 3D monopoles or horns). However studying the latter as possible UWB antennas is essential to find design rules for other technologies. Micro-strip antenna shapes, for example, are often inspired by projection of 3D existing antennas [1], [2]. Applying the consideration developed above, we focused on a modified simple monopole in order to minimize the dispersion. The ground plane was opened to enable a bi-directional radiation pattern in a first step although for UWB monopole it would be interesting to design a ground plane around the area of the radiating part as in [7] and [8] but this has the penalty of narrowing the bandwidth. Herein, the return loss criterion was preferred and the design antenna present characteristics of Figure 2, where the radiation pattern is shown for 3 frequencies in the UWB band.

The main lob is slightly moving in function of the frequency. This will undesirably distort any pulse shape transmitted by the antenna. A radio link is simulated between two antennas at 1 meter, to compare with the antenna surface: $7 \times 7 \mathrm{~cm}^{2}$. Results of the propagation link transfer function (or S21) are shown on Figure 3. The important variation of the magnitude is due to the free space path losses (FSPL) combined with main lobe frequency dependence discussed above and shown in Figure 2. The phase of S21 in function of the frequency was not reported on Figure 3 but was simulated to be linear, as it is often expected for small symmetrical UWB dipole (the phase centre trajectory is very small compared to the distance in farfield hypothesis) [5]. Now this transfer function, S21, can be used to characterise the modification of UWB pulses in our communication system. Other types of UWB antenna with a best control of the DDR, keeping the 3-10 GHz bandwidth and phase linearity, will be studied and designed at Supelec for the characterisation antenna deformation on UWB pulses.

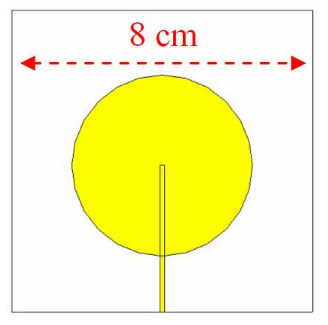

(a)

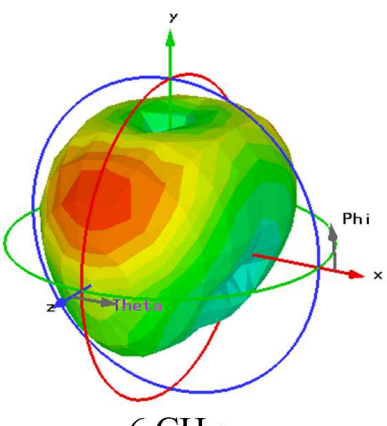

$6 \mathrm{GHz}$

(c)

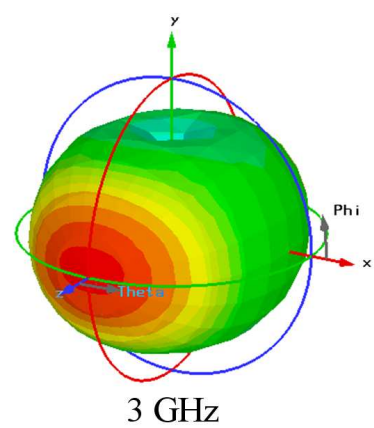

(b)

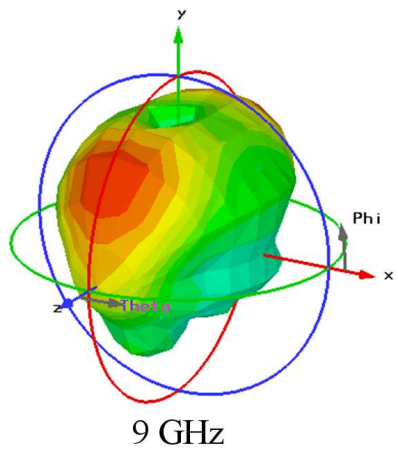

(d)
Figure 2. The antenna designed (a), the radiation pattern (b),(c),(d) and the configuration of the transfer

\section{SignAL PROCESSING}

We consider an Impulse Radio Time-Hopping Pulse Amplitude Modulation (binary IR-TH-PAM) UWB system [9]; the time is divided in frames, each frame is divided in $N_{h}$ slots with $T_{c}$ being the duration of a slot and an user send one impulse per frame in a slot position given by a pseudorandom time-hopping code. We note $w(t)$ the received pulse after the receiver antenna. We are interested in the effect of Multi-User Interferences, so we consider that the receiver is synchronized with user 1 (transmitter 1) and there are $N_{u}-1$ interfering users which are not synchronized with user 1. It is known [9], [10], [11] that the MUI in IR-TH are not Gaussian. After the correlation part of the receiver for each impulse of the received signal, it has be shown [12] that the MUI may be well fitted by a Generalized Gaussian which has the following probability density function:

$$
\begin{aligned}
& p(x)=\frac{c_{1}(\beta)}{\sqrt{\alpha^{2}}} \exp \left(-c_{2}(\beta)\left|\frac{x}{\sqrt{\sigma^{2}}}\right|^{\frac{2}{1+\beta}}\right) \\
& \text { with } c_{1}(\beta) \text { and } c_{2}(\beta) \text { functions of } \beta .
\end{aligned}
$$

When $\beta \neq 0$ the Generalized Gaussian is not a classical Gaussian. In a communication system where the interference has a Generalized Gaussian distribution, the capacity (maximum achievable rate) depends on the parameter $\beta$ of the Generalized Gaussian [11]. The parameter $\beta$ is linked to the 


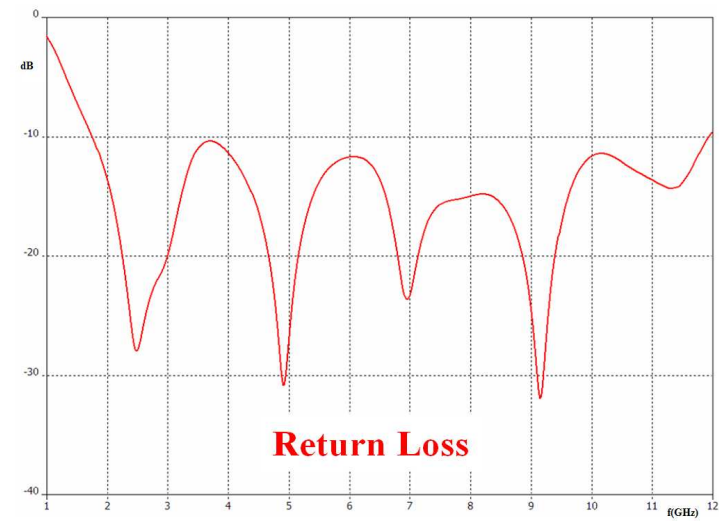

(a)

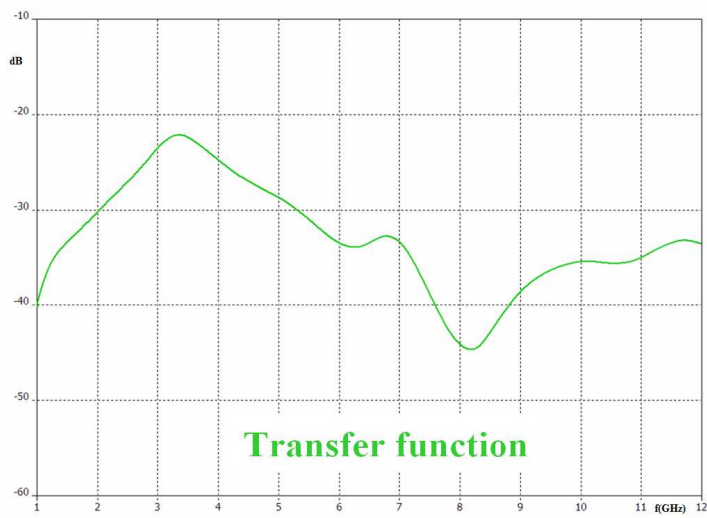

(b)

Figure 3. Return loss (a) and link transfer coefficient (b) at $1 \mathrm{~m}$

kurtosis $k$ of the MUI as we can see in the Figure 4, where is graphically represented the dependence $k(\beta)$.

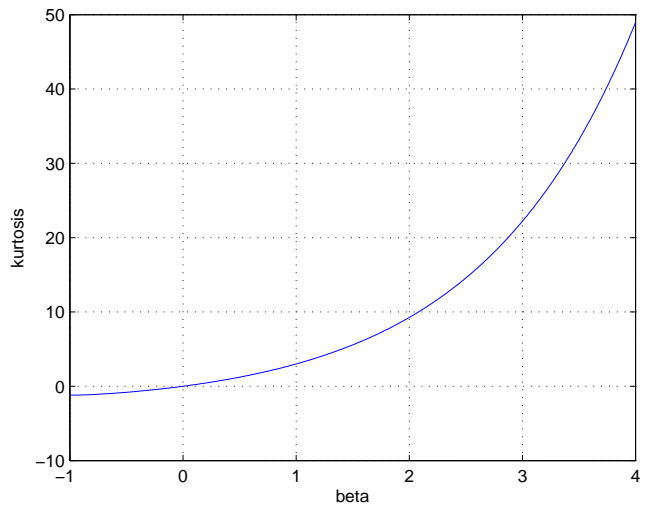

Figure 4. Kurtosis $(\beta)$

It is known that for a random variable $x$, the kurtosis is $k=\frac{E\left[x^{4}\right]}{E\left[x^{2}\right]^{2}}-3$. Based on this relationship, in [11] is given the equation linking the parameters of the signal to the kurtosis of the MUI:

$$
k=\frac{\left[\left(N_{u}-1\right) N_{h} m_{4}(w)+6 \frac{\left(N_{u}-1\right)\left(N_{u}-2\right)}{2} m_{2}^{2}(w)\right]}{\left[\left(N_{u}-1\right) m_{2}(w)\right]^{2}}-3
$$

with

$$
\begin{gathered}
m_{4}(w)=\frac{1}{T_{c}} \int_{-\infty}^{\infty} \gamma_{w}(z)^{4} d z \\
m_{2}(w)=\frac{1}{T_{c}} \int_{-\infty}^{\infty} \gamma_{w}(z)^{2} d z \\
\gamma_{w}(z)=\int_{-\infty}^{\infty} w(t+z) w(t) d t
\end{gathered}
$$

One can see that the kurtosis of the MUI depends not only on $N_{u}, N_{h}$ and $T_{c}$ but also on the shape $w(t)$ of the received impulse. So, the coefficient $\beta$ of the Generalized Gaussian probability density function depends on the shape $w(t)$ and as a consequence the capacity of the communication system depends also on $w(t)$. The detail of the computation of the capacity in function of the coefficient $\beta$ is given in [11]. By following this analysis we have compared the capacity of IRTH-PAM UWB systems using different pulse shapes at the output of the receiving antenna. This gives a new performance criterion of the pulse created through the antenna. The first pulse used is the pulse corresponding to the dirac impulse response of our antennas. Such a pulse has at the output of the received antenna a $-10 \mathrm{~dB}$ bandwidth of $4 \mathrm{GHz}$. The second pulse used is the classical Scholtz pulses used in many UWB studies [14], it is the second derivative of a Gaussian pulse. We have chosen the characteristics parameter of this Scholtz pulse to be such as having the same $-10 \mathrm{~dB}$ bandwidth as our first pulse $(4 \mathrm{GHz})$. The third pulsed used is the response of our antennas to a rectangle impulse input (100 ps square) which is easy to create with an impulse generator. Due to the transfer function of our antennas the received impulse has a bandwidth of $3.7 \mathrm{GHz}$. Thus we have consider a four impulse: the Sholtz impulse having a $-10 \mathrm{~dB}$ bandwidth of $3.7 \mathrm{GHz}$. Table 1 shows the performance of the communication with perfect power control [11] in term of achievable capacity (in bits per channel use which is bound by 1 bit/channel use for binary PAM) for some values of the parameters $N_{u}$ and $N_{h}$ with $T_{c}=0.25 \mathrm{~ns}$. We can see that the performance of Scholtz's pulse is reached by the pulse created by our antennas. Moreover, as expected when the $-10 \mathrm{~dB}$ bandwidth is larger, the capacity is better because the pulse is narrower leading to a more impulsiveness interference so a less Gaussian interference (which is the worst interference case [11]).

\section{RESULTS}

As in [11], for the simulations we have considered two possible scenarios: perfect power control and lack of power control, with the same network parameters and user distribution.

Table I

CAPACITY IN TERM OF BITS/CHANNEL USE FOR VARIOUS RECEIVED PUlse Shapes - PERFECT POWER CONTROL, Nu=100

\begin{tabular}{|c|c|c|}
\hline Received pulse shape & $\mathrm{Nh}=100$ & $\mathrm{Nh}=250$ \\
\hline \hline Dirac response of our antennas & $0.713 \mathrm{~b} / \mathrm{ch} . \mathrm{u}$. & 0.911 b/ch.u. \\
\hline Scholtz pulse 4GHz -10dB bandwidth & $0.653 \mathrm{~b} / \mathrm{ch} . u$. & 0.880 b/ch.u. \\
\hline Resp. of antennas to a 100ps sq. pulse & $0.616 \mathrm{~b} / \mathrm{ch} . u$. & $0.863 \mathrm{~b} / \mathrm{ch} . u$. \\
\hline Scholtz pulse $3.7 \mathrm{GHz}-10 \mathrm{~dB}$ bandwidth & $0.630 \mathrm{~b} / \mathrm{ch} . u$. & $0.867 \mathrm{~b} / \mathrm{ch} . u$. \\
\hline
\end{tabular}

By comparison with the second table, we could observe that the capacity is decreasing for the lack of power control 
scenario and also the capacity gap between the considered cases modifies.

Table II

CAPACITY IN TERM OF BITS/CHANNEL USE FOR VARIOUS RECEIVED PULSE SHAPES - LACK OF POWER CONTROL, NU $=100$

\begin{tabular}{|c|c|c|}
\hline Received pulse shape & $\mathrm{Nh}=100$ & $\mathrm{Nh}=250$ \\
\hline \hline Dirac response of our antennas & 0.239 b/ch.u. & 0.509 b/ch.u. \\
\hline Scholtz pulse 4GHz -10dB bandwidth & 0.207 b/ch.u. & 0.465 b/ch.u. \\
\hline Resp. of antennas to a 100ps sq. pulse & 0.177 b/ch.u. & 0.421 b/ch.u. \\
\hline Scholtz pulse 3.7GHz -10dB bandwidth & 0.190 b/ch.u & 0.443 b/ch.u. \\
\hline
\end{tabular}

In Figure 5 we have compared the dirac response of our antennas (a) and the response of the antennas to a square pulse (b) with the Scholtz's pulse. As one can see, each figure contains the Capacity as a function of SIR and $\beta$ for each type of considered response. The evaluation has been done in 5 points - denoted on the graph with $1,2,3,4$ an 5 respectively and corresponding to the next pairs $\left(N_{h}, N_{u}\right)$ : $\left(N_{h}=100, N_{u}=100\right) ;\left(N_{h}=250, N_{u}=100\right) ;\left(N_{h}=500, N_{u}=100\right)$; $\left(N_{h}=500, N_{u}=50\right) ;\left(N_{h}=1000, N_{u}=50\right)$.
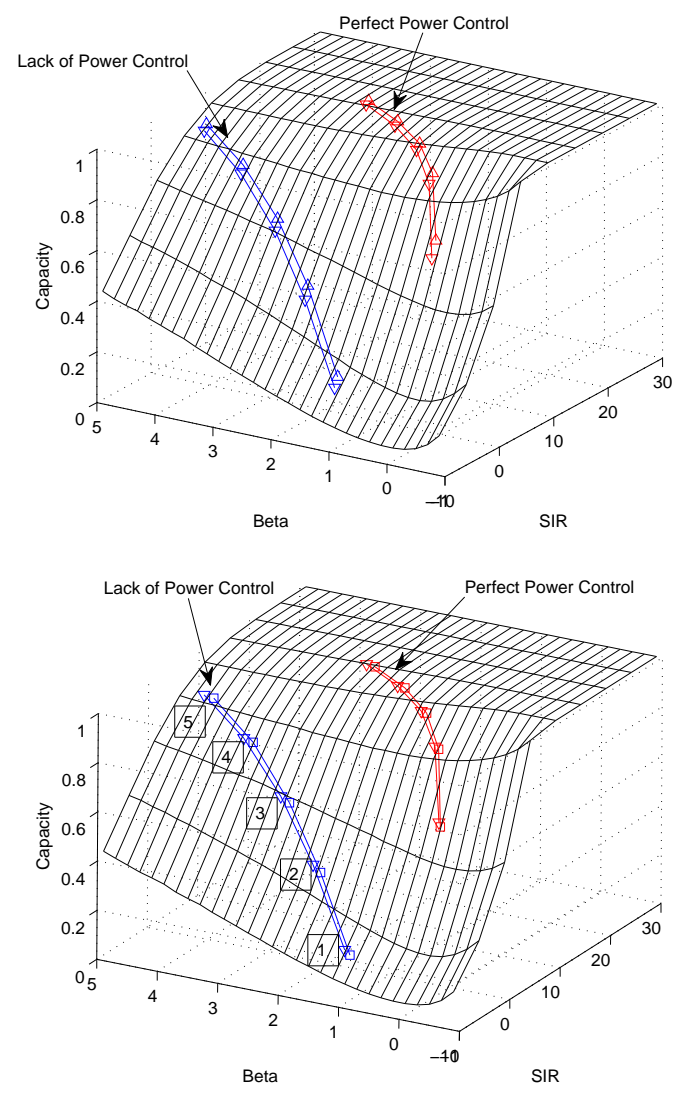

Figure 5. Capacity(SIR, $\beta$ ) with (a) Dirac response of antennas ' $\triangle$ ' vs Sholtz's pulse ' $\nabla$ ' and (b) Response of antennas to a square pulse ' $\square$ 'vs. Sholtz's pulse ' $\nabla$ '

Last but not least, we have reached the conclusion that the response of the antennas to a square signal of 70ps is the perfect equivalent in terms of capacity to the Sholtz's pulse with the same bandwidth at $-10 \mathrm{~dB}(3.84 \mathrm{GHz}$, corresponding to a pulse of $306 \mathrm{~ns}$ ).

\section{Conclusions}

We have developed an Ultra Wide Band antenna and proposed a new performance criterion: the communication capacity (achievable bit rate) in presence of the MUI modeled by the pulse shape fashioned by the antenna. The development of this study should lead to the investigation of more UWB antennas and pulse shapes optimizations.

\section{REFERENCES}

[1] M. Ghavami, L. Michael and R. Khono. "UWB signals and systems in communications engineering" Wiley 2004.

[2] H. Shantz. "A brief history of UWB antennas" Proceedings of IEEE UWB Systems and Technologies, 2003.

[3] M. A. Peyrot-Solis and al. "State of the Art in UWB Antennas" 2nd International Conf. on Electrical and Electronics Engineering (ICEEE), Mexico, Sept. 2005.

[4] D. C. Cheng. "Update various kinds of UltraWideBand antennas" IEEE UWB Symposium 2005, Taiwan.

[5] T. Ma, S. Jeng. „Planar miniature tapered slot fed annular slot antennas for UWB radios" IEEE transactions on Antennas and Propagation, $N^{\circ} 3$, 2005 pp 215-226.

[6] H. Schantz. "The Art and Science of UltraWideBand Antennas" Artech House, 2005.

[7] Y. Chawanonphithak, C. Phongcharoenpanish. "A circular microstrip antenna with tuning stub above wide-slot ground plane for band-notched UWB using inverted U-slot" Proceedings of Asia-Pacific Microwave Conference, APMC 2007.

[8] K. Chawanonphithak, C. Phongcharoenpanish, S. Kosulvit, M. Krairiksh. "5.8 GHz notched UWB bidirectional elliptical ring antenna excited by circular monopole with curved slot" Proceedings of AsiaPacific Microwave Conference, APMC 2007.

[9] M. G. Di Benedetto, G. Giancola, "Understanding Ultra Wide Band, Radio Fundamentals", Upper Saddle River, New Jersey: Prentice Hall Pearson Education, Inc., 2004.

[10] J. Fiorina and W. Hachem "On the Asymptotic Distribution of the Correlation Receiver Output for Time-Hopped UWB Signals," in IEEE Transactions on Signal Processing, Volume 54, Issue 7, July 2006 pp $2529-2545$.

[11] J. Fiorina, D. Domenicali "Revisiting TH-IR-UWB performance limits dependency on essential system parameters using the Generalized Gaussian Approximation" IEEE International Conference on Ultra Wideband (ICUWB'07), Sept 24 - 26, 2007, Singapore.

[12] J. Fiorina, "A Simple IR-UWB Receiver Adapted to Multi-User Interferences", 27 Nov - 1 Dec, Globecom 2006, San Francisco.

[13] M. Z. Win et R. A. Scholtz, "Ultra-Wide Bandwidth Time-Hopping Spread-Spectrum Impulse Radio for Wireless Multiple-Access Communications", IEEE Transactions on Communications, Vol.48, No.4, Avril 2000.

[14] M. Z. Win and R. A. Scholtz, "Impulse Radio: How it works", IEEE Communications Letters, vol.2, no.2, pp.36-38, February 1998. 